\title{
The lengthy high-stress consolidation test research on silty clay in Xi'an
}

\author{
Gangchen Sun ${ }^{1,2, a}$, Jianbing Peng ${ }^{2, b}$ \\ ${ }^{1}$ Chang an University, Xi'an 710054, China \\ 2 Guilin University of Technology, Guilin 541004, China \\ asun2963@163.com, bdicexy_1@chd.edu.cn
}

Keywords: silty clay; lengthy high-stress consolidation test; rheological deformation; subsidence calculation

Abstract. The long-term high-pressure consolidation test, of which the maximum consolidation pressure is $6 \mathrm{MPa}$ and the longest consolidation duration is 34 months, is selected to simulate the deformation characteristics of the main compression soil layer (depth of $100 \sim 300 \mathrm{~m}$ ) based on the study of the deep foundation pit silty clay located in Xiaozhai subway station in Xi'an City. The test results shows that Terzaghi's one-dimensional consolidation theory of soil is no longer applicable to the soil consolidation calculation and prediction as the consolidation stress exceed 4.8MPa; under the pressure of $6 \mathrm{MPa}$, the rheological deformation accounts for about $90 \%$ of the total deformation, and the deformation shows no signs of stopping after compression for 953 days; when the stress is reduced or removed, most of the compression deformation of soil is not recoverable.

\section{Introduction}

In Xi'an, the ground subsidence is mainly caused by the release of water in the soil below ground in the range of $100-300 \mathrm{~m}^{[1-3]}$. For calculating and predicting the settlement of the ground in Xi'an, a long-term high-pressure consolidation test on the Xi'an silty clay is carried out to study its deformation characteristics.

\section{Test Method}

The WG-type triple lever high pressure consolidation instrument from Nanjing soil instrument factory is used in this paper, shown in Fig.1. The soil sample is selected from the deep foundation pit construction site, its depth is about 16 meters underground, located in the Xiaozhai subway station in Xi'an city. The sum of the soil testes is three. According to the drilling engineering data of Xi'an Engineering and Technology School, the soil samples are prepared with about $23 \%$ water content, and pressed into soil column in the humidifier and then stood for two weeks for using with the ring knife. The initial physical parameters of the test soils are shown in Table 1; the test loading order, the pressure level and the loading duration are shown in Table 2.

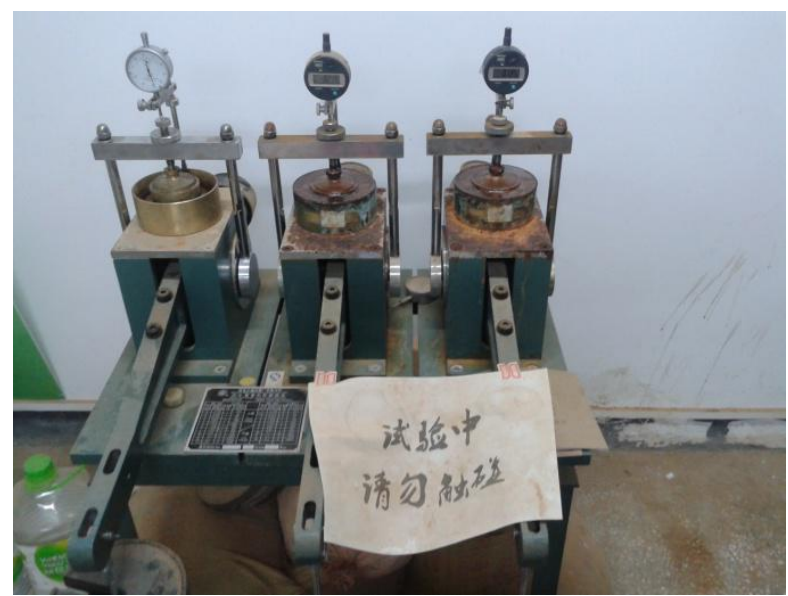

Fig. 1 WG high pressure consolidation apparatus 
Table 1 Initial parameters of soil samples

\begin{tabular}{cccccccc}
\hline $\begin{array}{c}\text { Sample } \\
\text { NO. }\end{array}$ & $\begin{array}{c}\text { Porosity } \\
\text { ratio }\end{array}$ & Density $\rho\left(\mathrm{g} / \mathrm{cm}^{3}\right)$ & $\begin{array}{c}\text { Water } \\
\text { content } \omega\end{array}$ & $\begin{array}{c}\text { Proportion of soil } \\
\text { particles } G_{s}\end{array}$ & $\begin{array}{c}\text { density } \\
\left(\mathrm{g} / \mathrm{cm}^{3}\right)\end{array}$ & $\begin{array}{c}\text { Plastic } \\
\text { limit }\end{array}$ & $\begin{array}{c}\text { Liquid limit } \\
\omega_{p}\end{array}$ \\
\hline Sample 1 & 0.679 & 2.13 & $23.408 \%$ & & & & \\
Sample 2 & 0.6247 & 2.08 & $22.664 \%$ & 2.704 & 1.789 & 18.6 & 30.16 \\
Sample 3 & 0.6889 & 2.10 & $24.095 \%$ & & & \\
\hline
\end{tabular}

Table 2 Loading procedure and duration $/ \mathrm{h}$

\begin{tabular}{ccccc}
\hline Loading order & Pressure $(\mathrm{MPa})$ & Sample 1 duration & Sample 3 duration & Sample 3 duration \\
\hline 1 & 0.4 & 48 & 48 & 48 \\
2 & 0.8 & 48 & 48 & 48 \\
3 & 1.6 & 72 & 72 & 72 \\
4 & 3.2 & 72 & 72 & 144 \\
5 & 4.8 & 144 & 144 & 24 \\
6 & 3.2 & 24 & 24 & 72 \\
7 & 4.8 & 72 & 72 & 96 \\
8 & 5.6 & 96 & 96 & 192 \\
9 & 6 & 192 & 192 & 96 \\
10 & 4.8 & 96 & 96 & 22872 \\
11 & 6 & 3606 & 22872 & 360 \\
12 & 4.8 & & 360 & 312 \\
13 & 3.2 & & 312 & 336 \\
14 & 1.6 & & 336 & 264 \\
15 & 0.4 & End of the tests & 264 & \\
\end{tabular}

\section{Test data analysis}

1. Changes of soil moisture content before and after the test

After the test, the upper, middle and lower parts of the soil samples are tested for moisture content by drying method, shown in Table 3.

Table 3 Moisture content of soil samples before and after test $\%$

\begin{tabular}{|c|c|c|c|c|c|c|}
\hline \multirow[b]{2}{*}{ Soil sample } & \multicolumn{4}{|c|}{ After test } & \multirow[b]{2}{*}{$\begin{array}{c}\text { Calculated } \\
\text { Value }\end{array}$} & \multirow[b]{2}{*}{ Before test } \\
\hline & Upper parts & Middle parts & Lower parts & Mean Value & & \\
\hline Sample 1 & 14.496 & 14.594 & 14.467 & 14.519 & & 23.406 \\
\hline Sample 2 & 10.756 & 12.255 & 11.491 & 11.50 & 9.600 & 22.664 \\
\hline Sample 3 & 13.691 & 13.513 & 12.461 & 13.22 & 10.920 & 24.095 \\
\hline
\end{tabular}

The moisture content of sample 1 is less than that of sample 2 and sample 3 , and the measured water content of soil samples is about $20 \%$ higher than the calculated value. The minimum water content of the soil samples is about $13.8 \%$ at about $300 \mathrm{~m}$ depth according to the survey data of stratified specimens of Engineering and Technical School in Xi'an city, and the moisture content of the silty clay that is subjected to long-term pressure consolidation with the actual formation vertical pressure in this experiment is similar to that of the natural formation.

2 Soil sample deformation curve analysis 
According to the experimental records, the pressure-deformation curve (e-logp) and the deformation-time curve (e-logt) of each soil sample under various pressure are plotted in Fig.2 and Fig.3.

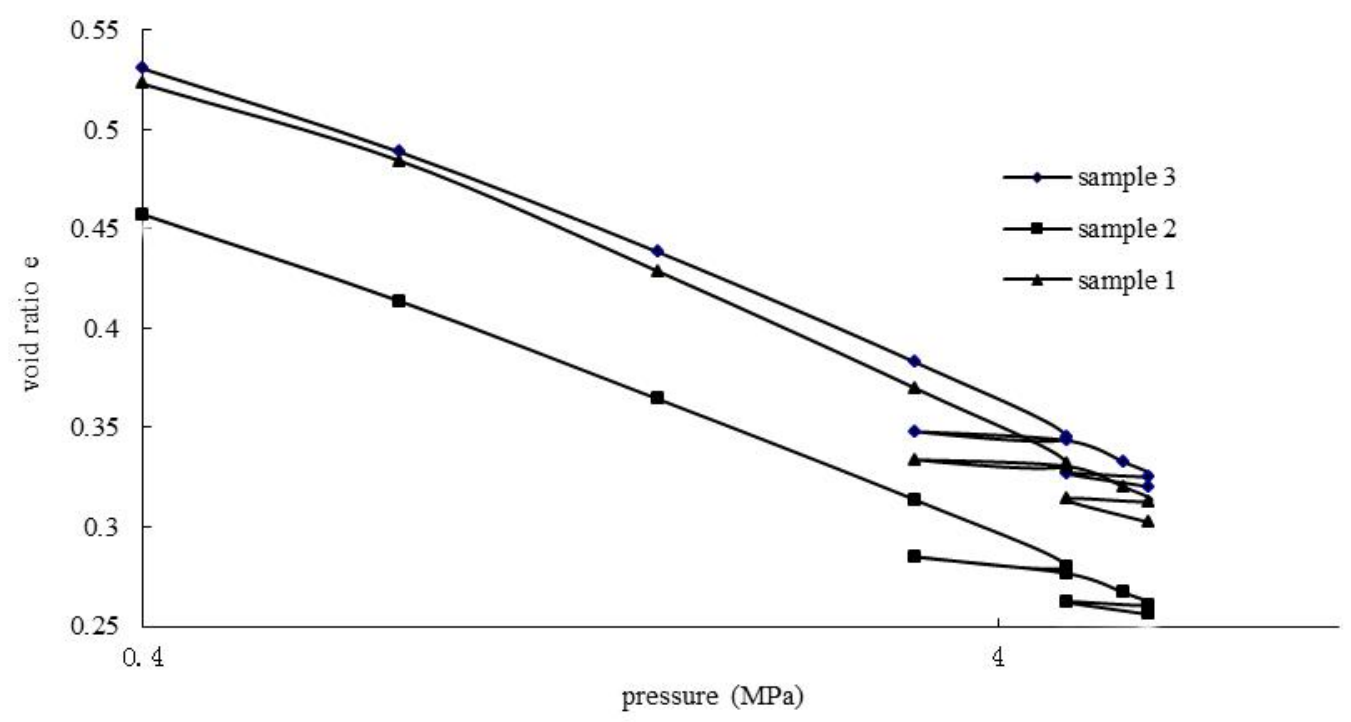

Fig.2 Plot of void ratio versus pressure

According to the test data and Fig.2 3, the soil sample's stress-deformation curves have the following characteristics: the unloading curves of all soil samples are approximately horizontal, and the proportion of recoverable deformation is very small. Under the action of 6.0 MPa pressure, the compressive deformation has satisfied the stability requirement after $96 \mathrm{~h}$, but still has a large compression deformation after, shown in Table 4 and Fig.3. The ratio of compression deformation to the respective total one is at the range of $86.27 \%-95.90 \%$ until reaching to the $96 \mathrm{~h}$ experimental duration or to the test end. Considering the geological environment in which the main compression soil layer in Xi'an, this part of the soil will be in a compressed state for a long period of time after the water level drops, and the amount of compression deformation cannot be neglected.

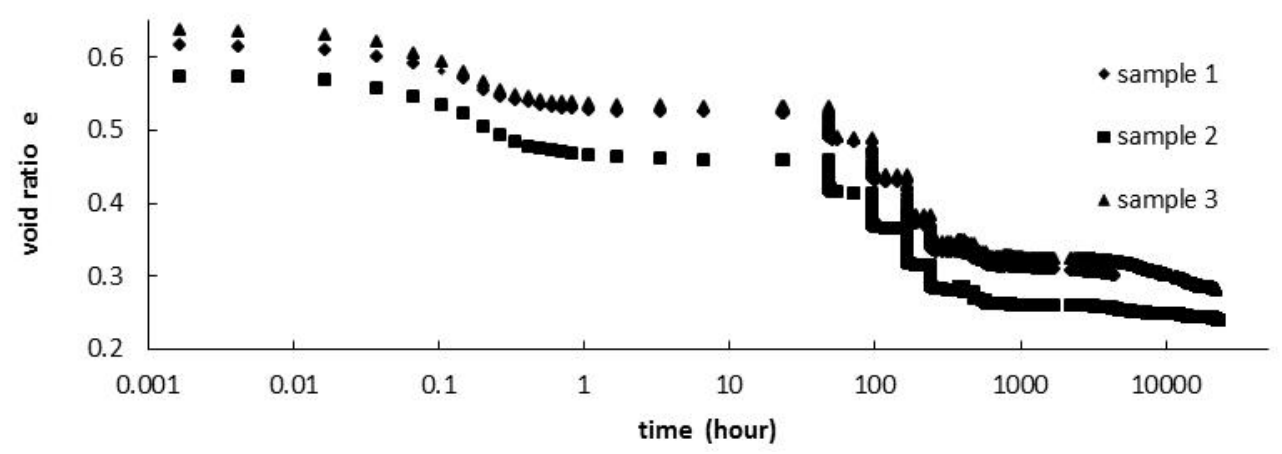

Fig.3 Plot of void ratio versus time

Table 4 Deformation of soil under the stress of 6.0 MPa

mm

\begin{tabular}{ccc}
\hline 96h compression & Final compression & The soil compression ratio of the one from $96 \mathrm{~h}$ to the test end to the total compression one / \% \\
\hline 4.376 & 4.508 & 86.27 \\
4.486 & 4.744 & 90.53 \\
4.31 & 4.895 & 95.90 \\
\hline
\end{tabular}

From the one-dimensional consolidation theory, it can be proved that the deformation-time curve like "S" shape with the sample 2 in the case of linear or approximately linear loading procedure ${ }^{[4]}$. The 
deformation-time curve of the soil sample 2 is a typical "S-shape" curve with the small pressure, but the curve is no longer obvious in this shape with the increase of pressure, shown in Fig.4. The change of the curve shape shows that the Terzaghi one-dimensional consolidation theory is no longer applicable to the calculation and prediction of the consolidation of soil samples when the pressure exceeds a certain threshold.

0. $4 \mathrm{MPa}$

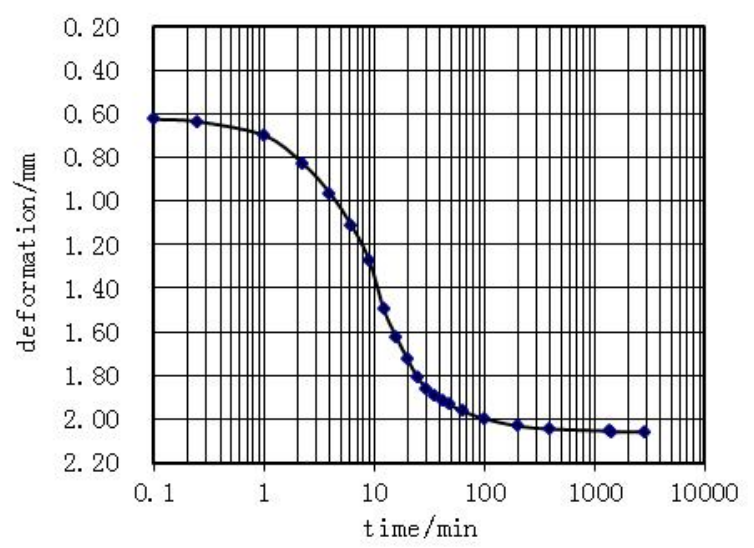

$5.6 \mathrm{MPa}$

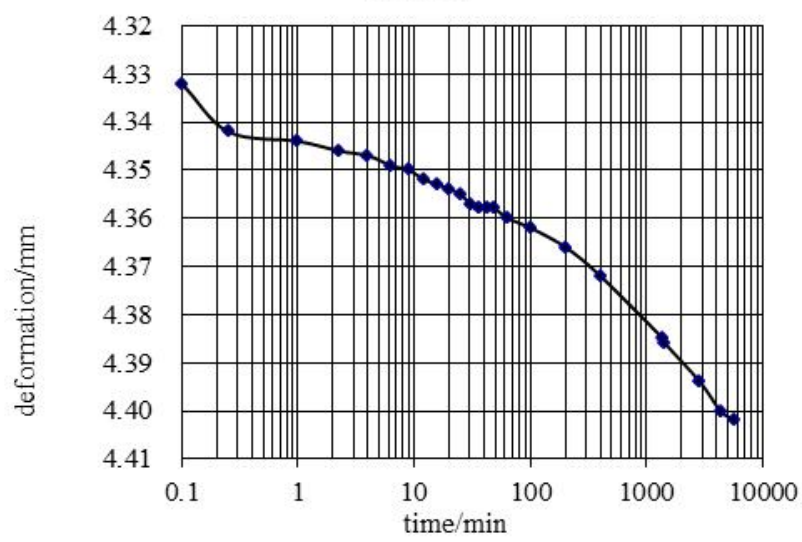

Fig.4 Plot of deformation versus time at first under first loading of sample 2

\section{Conclusion and Suggestions}

The rheological deformation of silty clay in Xi'an is about $90 \%$ of the total deformation under the same level load, and after nearly three years of consolidation and deformation, there is still no sign of stopping. Therefore, the time effect of the consolidation of the silty clay should be taken into account in the calculation of ground subsidence in Xi'an city. According to the results of this experiment, Terzaghi one-dimensional consolidation theory is no longer applicable to the calculation and prediction of consolidation and deformation of soil samples when the pressure exceeds $4.8 \mathrm{MPa}$. Subsequent tests should be conducted with different depths of soil samples for systematic testing to determine the applicability of soil consolidation theory such as Terzaghi consolidation theory. The proportion of recoverable deformation is very small in silty clay compression deformation. Therefore, the main idea should be based on prevention for the subsidence.

\section{Acknowledgements}

This work was financially supported by Patent doubling plan of Guangxi project (2013ZL081) and National Natural Science Foundation of China (No.41130753, No.41062006).

\section{References}

[1] Gangchen Sun, Jianbing Peng, Deyuan Zhang:Journal of Catastrophology (In Chinese).Vol.23(s) (2008), p.40-44

[2] Peng Jianbing:Disaster of Xi'an ground Fissures. Chinese Science and Technology Publising, Beijing(2012)

[3] Wang Qiyao,Peng Jianbing,Jiang Zhenwei:Rock and Soil Mechanics,Vol.35 (2014), p. 3298-3309

[4] Liu Zitong,Mei Guoxiong, Zai Jinmin: Journal of Nanjing University of Technology, Vol. 25 (2003), p. 1-3 